\title{
Os gêneros textuais e o ensino da compreensão leitora: uma análise de livros didáticos do ensino médio
}

\author{
Adriana Morais Jales* \\ Camila Bezerra Freire** \\ Débora Brenda Teixeira Silva***
}

\section{Resumo}

Considerando a relevância dos gêneros textuais ao ensino de línguas, este trabalho tem por finalidade analisar como as atividades de leitura são orientadas nos livros didáticos de Língua Inglesa do Ensino Médio com vistas ao letramento crítico. Esta produção é um recorte de um estudo vinculado ao Programa Institucional de Bolsas de Iniciação Científica (PIBIC/ CNPq 2019/2020). Nesse sentido, analisamos a coleção Way to Go e como parâmetros de análise, levamos em consideração a indicação de gênero textual, propósito comunicativo, forma composicional, suporte e a orientação para o posicionamento crítico dos alunos. Diante de nossos resultados, percebemos que a maioria das unidades apontam atividades embasadas em gêneros textuais, indicando a forma composicional, suporte e atenção ao desenvolvimento da criticidade dos alunos. No tocante ao propósito comunicativo, vimos que muitas atividades deixam de atender a esse critério. A coleção estudada apresenta, portanto, uma adequação parcial com as teorias relacionadas a este estudo.

Palavras-chave: Gêneros textuais; Leitura; Livro didático; Língua Inglesa.
* Possui graduação em Letras pela Universidade do Estado do Rio Grande do Norte (1995), especialização em Língua Inglesa pela Universidade do Estado do Rio Grande do Norte, mestrado em Linguística Aplicada pela Universidade Estadual do Ceará (2007) e Doutorado em Estudos da Linguagem pela Universidade Federal do Rio Grande do Norte (2015) com dois Doutorados Sanduíches, sendo o primeiro pelo Programa Nacional de Cooperação Acadêmica (PROCAD-NF), na PUC e na USP, em 2012 e o segundo na Universidade de Aarhus - Dinamarca sob a orientação do Prof. Dr. Henning Nlke (2013-2014). Atualmente é professora do Departamento de Letras Estrangeiras (DLE/FALA) da Universidade do Estado do Rio Grande do Norte, no Campus Central - Mossoró - RN e do Mestrado Profissional em Letras - PROFLETRAS; Líder do Grupo de Pesquisa em Linguística e Literatura - GPELL; Coordenadora de Área do Subprojeto Letras/ Língua Inglesa do Programa Institucional de Bolsas de Iniciação à Docência - PIBID/CAPES. Tem experiência na área de Linguística, com ênfase em Linguística Aplicada, atuando principalmente nos seguintes temas: análise do texto e do discurso, linguística enunciativa, leitura, escrita, ensino de língua inglesa, gêneros textuais/discursivos e análise de livro didático. E-mail: adrianajales@uern.br

** Universidade do Estado do Rio Grande do Norte: Mossoro, RN, BR. E-mail: camila.bezerrafreire@gmail.com

**** Mestrado Acadêmico em andamento pelo Programa de Pós-Graduação em Ciências da Linguagem (PPCL/ UERN). Graduada em Letras - Língua Inglesa pela Universidade do Estado do Rio Grande do Norte - UERN (2020). Atuou como aluna pesquisadora pelo Programa Institucional de Bolsas de Iniciação Científica (PIBIC), participando atualmente como integrante voluntária de grupo de estudo vinculado ao Grupo de Pesquisa em Linguística e Literatura (GPELL - UERN). Participou como bolsista residente do Programa Residência Pedagógica, subprojeto de Língua Inglesa da UERN (CAPES, 2018-2020). Foi professora bolsista do Núcleo de Estudo e Ensino de Línguas (NEEL, 2017 - 2019) do Departamento de Letras Estrangeiras - DLE. Participou de duas edições do Programa Institucional de Bolsas de Iniciação à Docência (PIBID/CAPES), subprojeto de Letras/Língua Inglesa (2016-2017; 2018). Desenvolve estudos na área de Linguística de Texto, com interesse e atuação pelos seguintes temas: Análise de Discurso Crítica ( $\mathrm{ADC}$ ), gêneros textuais/discursivos, leitura e produção escrita, livro didático e ensino.E-mail: deborateixeira94@hotmail.com

Data de submissão: abr. 2021 - Data de aceite: jul. 2021

http://dx.doi.org/10.5335/rdes.v17i2.12612 


\section{Considerações iniciais}

No campo da linguagem, têm-se desenvolvido muitos estudos acerca da perspectiva sociointeracional de ensino e aprendizagem, como também a respeito do ensino de línguas voltado para gêneros textuais (ANTUNES, 2003; KOCH; ELIAS, 2012). Diante disso, é possível observarmos que apesar da grande aceitação desta concepção no meio escolar, ainda há dificuldades para a realização dessa abordagem na prática. Antunes (2002) argumenta que a escola continua a fazer com o texto mais ou menos o que fazia antes. Isso acontece porque, muitas vezes, a noção estruturalista de língua ainda intervém nas práticas dos profissionais da educação. Dessa forma, o texto acaba sendo visto apenas como objeto de exemplificação para algum item gramatical.

É importante destacar que essa perspectiva está inserida nas recomendações dos documentos oficiais de ensino, como os Parâmetros Curriculares Nacionais - PCN (BRASIL, 1998, 2001), os Parâmetros Curriculares Nacionais para o Ensino Médio - PCN+ (BRASIL, 2006), as Orientações Curriculares para o Ensino Médio - OCEM (BRASIL, 2006) e a Base Nacional Comum Curricular BNCC (BRASIL, 2018).

Como consequência da realidade do ensino de línguas voltada para o gênero, surgem muitos questionamentos acerca da qualidade de tal ensino, levando em consideração o desenvolvimento da compreensão de texto do aluno, a construção do seu senso crítico e a coerência do material didático com os documentos oficiais. No que tange ao livro didático, os questionamentos também se tornam válidos, visto que é a principal ferramenta utilizada pelo professor em sala de aula.

Desse modo, o presente artigo tem por objetivo analisar como são orientadas as atividades de leitura do livro didático de Língua Inglesa do Ensino Médio com vistas ao letramento crítico. Para tanto, investigamos os livros didáticos da coleção Way to Go (2016) ${ }^{1}$, utilizada em uma das três maiores escolas da cidade de Mossoró - RN.

Para a realização desta pesquisa, estabelecemos três objetivos específicos, responsáveis por orientar nosso estudo. São estes: (a) Averiguar quais gêneros textuais são trabalhados nas atividades de leitura nos livros didáticos do Ensino Médio; (b) Verificar se os autores do livro didático do Ensino Médio abordam as características dos gêneros textuais utilizados nas atividades de leitura; (c) Investigar se os autores da coleção orientam os alunos a se posicionarem frente ao texto nas atividades de leitura.

Como base para o nosso estudo, utilizamos os trabalhos dos autores: Antunes (2002, 2003), Bakhtin (2003), Koch e Elias (2012), Marcuschi (2005, 2008), Solé (1998), entre outros. Ademais, salientamos que esta é uma pesquisa 
vinculada ao Programa Institucional de Bolsas de Iniciação Científica (PIBIC/ CNPq - 2019/2020).

Este trabalho se encontra organizado a partir de uma seção introdutória do tema, seguida da fundamentação teórica, subdividida em duas linhas principais: uma a respeito das concepções acerca dos gêneros textuais e outra em que apresentamos algumas reflexões sobre o ensino da leitura. Na sequência, trazemos a metodologia, na qual detalhamos os procedimentos utilizados em nosso estudo. Em seguida, apresentamos nossos resultados e a discussão dos dados. Finalizamos, então, com algumas considerações finais sobre nosso estudo e inserimos, por fim, as referências utilizadas.

\section{Gêneros textuais: concepções teóricas}

Nos últimos anos, estudos sobre a temática de gêneros textuais e suas contribuições ao ensino de línguas têm sido intensificados (ANTUNES, 2009; MARCUSCHI, 2003). À vista disso, salientamos que, apesar de esses estudos datarem de anos atrás, muito ainda há que ser explorado, principalmente na área da Linguística Aplicada. Considerando que são diversas as perspectivas teóricas que estão envoltas a esse objeto (MARCUSCHI, 2008), apresentamos aqui algumas reflexões para embasar nossas discussões.
De acordo com Bakhtin (2003), a realização da língua somente ocorre por meio de enunciados, sejam estes orais ou escritos. Esses enunciados, chamados pelo autor de gêneros do discurso, possuem concretude, unicidade e surgem em decorrência de condições singulares de uso. Para Bakhtin (2003), esses enunciados são caraterizados por três elementos essenciais: conteúdo temático, estilo e construção composicional. É importante destacar que

[...] cada enunciado particular é individual, mas cada campo de utilização da língua elabora seus tipos relativamente estáveis de enunciados, os quais denominamos gêneros do discurso (BAKHTIN, 2003, p. 262).

A partir desse autor, podemos entender que o conteúdo temático diz respeito ao núcleo objetal presente nos gêneros do discurso, ou seja, é o assunto que normalmente se materializa em determinados enunciados. No que concerne ao estilo, o teórico russo afirma que em todo e qualquer enunciado há a presença de estilo que é parte inerente à língua, ao contexto e ao campo de produção e que reflete a individualidade do interlocutor. A construção composicional, por sua vez, refere-se às partes que compõem a formação do gênero (BAKHTIN, 2003).

Bakhtin (2003) critica a utilização de termos como ouvinte e falante. Isso porque, nos processos de comunicação, tanto aquele que fala como aquele que escuta realiza complexos esforços mentais, não cabendo a nenhuma parte um caráter 
passivo. Dizer que há ouvinte e falante, coloca o primeiro em uma categoria menos desenvolvida, como se ele não fosse necessário para a realização da comunicação. Para o filósofo russo, o interlocutor possui uma ativa posição responsiva, ainda que não diga nada. À vista disso, Bakhtin afirma que "toda compreensão é prenhe de resposta, e nessa ou naquela forma a gera obrigatoriamente: o ouvinte se torna falante." (2003, p. 271).

Consoante a isso, Marcuschi afirma que a comunicação humana não seria possível a não ser por meio dos gêneros textuais, posto que "toda manifestação verbal se dá sempre por meio de textos realizados em algum gênero" (2008, p. 154). Para o linguista, é importante saber distinguir entre tipos textuais, gêneros e domínios discursivos.

Os tipos textuais são sequências linguísticas que compõem os textos e podemos categorizá-los em: narração, descrição, injunção, argumentação e exposição. De acordo com Marcuschi (2008), gênero textual é todo texto materializado em meio comunicativo e que, por isso, possui função, propósito e estilo. O domínio discursivo, por sua vez, remete ao campo social do falante da língua, ou seja, às situações de comunicação nas quais estamos inseridos. A exemplo, podemos ressaltar o domínio discursivo religioso e o domínio discursivo jurídico.

Diante disso, Koch e Elias (2012) corroboram as características dos gêne- ros, destacando a composição, propósito, veículo, conteúdo e estilo. A composição ou forma composicional diz respeito à estruturação do texto, em outras palavras, é a sua organização padrão. O propósito é a intenção comunicativa presente e revelada pelo gênero. $O$ veículo se refere ao suporte pelo qual o gênero se manifesta. O conteúdo, por sua vez, é o tema característico. Já o estilo é revelado na construção do próprio gênero e também nas características individuais expressadas pelos participantes do discurso.

Para Marcuschi (2008), os gêneros são sócio-históricos e, por essa razão, surgem e se adaptam aos contextos da atualidade. Tendo isso em vista, Antunes (2002) também aponta que gêneros textuais são construídos historicamente, isto é, aparecem, sofrem modificações e/ou, até mesmo, desaparecem com o passar dos anos, sempre de acordo com a necessidade comunicativa das pessoas.

Bazerman, inserido em uma linha de tradição retórica, afirma que "o gênero é apenas a realização visível de um complexo de dinâmicas sociais e psicológicas" (2006, p. 29), ampliando e reafirmando a percepção de que os gêneros existem a serviço da comunicação. Segundo o autor, podemos compreender que os gêneros textuais se constroem a partir das práticas sociais que constituem.

Nessa mesma linha de raciocínio, Antunes ressalta "que o estudo da língua recobraria maior relevância de resultados 
se elegesse como objeto de estudo o texto, na sua dupla face de produção e recepção" (2002, p. 66). Se nos comunicamos por intermédio de textos, é basilar que o ensino se dê dentro dessa perspectiva. A respeito disso, Antunes inteira que o estudo alicerçado em gêneros textuais visa os "fatos linguístico-comunicativos" (2002, p. 71), com atenção à compreensão e à produção de textos variados $\mathrm{e}$ autênticos, sejam estes pertencentes a modalidade escrita ou oral. A seguir, versamos sobre a leitura e seu ensino.

\section{Leitura: perspectivas e reflexões}

É certo dizer que a leitura é uma das ferramentas mais importantes da educação. Desde cedo, as crianças são inseridas em momentos de leitura compartilhada e individual, a fim de que se tornem pessoas letradas. Quando inserido no contexto educacional, o letramento torna-se uma questão de ainda maior responsabilidade. Diante disso, faz-se necessário que as práticas de leitura em sala de aula não sejam apenas uma apresentação e decodificação de textos, mas de fato um ensino de leitura, levando em consideração uma série de aspectos imprescindíveis para que isso aconteça.

Para Solé (1998), a leitura é, antes de tudo, um processo interativo do qual participam leitor e texto. Nessa perspectiva, os sujeitos trabalham em conjunto para a construção da compreensão leitora. Consoante a isso, Koch e Elias (2012) afirmam que o sentido de um texto só é realizado mediante a interação autor-texto-leitor, não sendo algo preexistente a esse processo. Por causa disso, diversas interpretações podem surgir de um mesmo texto, a depender dos conhecimentos linguísticos, dos conhecimentos de mundo e dos conhecimentos interacionais do leitor, ideia essa apresentada por Koch e Elias como "três grandes sistemas de conhecimento" (2012, p. 39).

Além dos conhecimentos prévios, o objetivo da leitura é um grande norteador da produção de sentido. Este elemento aponta que a interpretação obtida em determinado texto depende do propósito que moveu a leitura em primeiro lugar. Assim, é possível que, por terem objetivos distintos, duas pessoas tenham interpretações diferentes de um mesmo texto (SOLÉ, 1998).

Solé (1998) argumenta que as intenções da leitura estabelecem tanto as estratégias de compreensão utilizadas, como o controle que o leitor terá sobre a leitura. Dessa forma, ele entra em um estado chamado por Brown de "estado de piloto automático" (1980 apud SOLÉ, 1998, p. 41). Esta é a posição na qual o leitor possui domínio daquilo que está lendo e, por isso, passa a solucionar problemas de compreensão com mais facilidade. O leque de gêneros também afeta a compreensão que se tem dos textos. 
Levando em consideração as sensações adquiridas através da leitura, Solé (1998) discorre sobre a necessidade de motivar o aluno para essa atividade, principalmente os leitores iniciantes. Antunes (2003) também destaca que, além de possibilitar conhecimento, a leitura é veículo de comunicação e prazer. Concordante a isso, podemos mencionar a relevância dos materiais utilizados na escola, a fim de que sejam atraentes ao aluno e possibilitem o desenvolvimento da compreensão dos textos (SOLÉ, 1998).

É notório que o professor possui o livro didático como principal ferramenta de ensino, tendo a função de orientar os docentes e de apresentar discussões pertinentes para a evolução dos alunos. No entanto, quando se trata de atividades de compreensão leitora, Marcuschi (2008) discute que os livros didáticos vêm apresentando falhas em tais exercícios de compreensão. Isto acontece principalmente por causa da noção de língua empregada, da visão de textos como produto finalizado e da perspectiva de que a compreensão acontece somente através da decodificação de tais textos.

Partindo do pressuposto de Solé de que "ler é compreender" (1998, p. 44), consideramos adequado que os autores dos livros didáticos exponham, em suas atividades, reflexões nas quais os alunos possam participar como leitores ativos e não como meros expectadores de conteúdo. Marcuschi (2008) também defende a ideia de que ler é o mesmo que ler de forma compreensiva. Diante disso, é basilar que os alunos-leitores adentrem em experiências de "aprendizagem significativa” (AUSUBEL, 1963 apud SOLÉ, 1998 , p. 44), nas quais se tem a oportunidade de reunir conhecimentos prévios, inclusive, nos livros didáticos de línguas estrangeiras, como a Língua Inglesa.

No tocante à Língua Inglesa, é importante frisar que essa ganha novas dimensões conceituais em decorrência dos avanços globais e tecnológicos (DUBOC; FERRAZ, 2011). Consoante a isso, Duboc e Ferraz complementam que, além da noção de língua com função comunicativa, a Língua Inglesa tem assumido, cada vez mais, a função de "ferramenta crítica e participativa" (2011, p. 20). Nesse sentido, entendemos que essa noção precisa ser contemplada no ensino regular da língua, para que os alunos assumam um papel de participantes críticos e ajam em sociedade através dela.

Ao realizar uma revisão acerca dos novos letramentos, Duboc e Ferraz (2011) entendem que, englobando a concepção convencional de letramento como aquela que aborda a habilidade de leitura e escrita de determinada língua, os novos letramentos referem-se a uma expansão dessa concepção, compreendendo "aspectos sócio-ideológicos inerentes às práticas de leitura" (DUBOC; FERRAZ, 2011, p. 21) e assumem, também, um viés sociocultural, com base no letramento crítico. 
No que tange ao letramento crítico, este possui alicerce nos estudos críticos da educação, tomando por referência principalmente as contribuições de Paulo Freire, ainda que na atualidade assuma uma perspectiva diferenciada, posto que se volta para a discussão de assuntos sociais. O letramento crítico viabiliza a ampliação da percepção do aluno, levando-o a uma formação engajada e posicionada a partir de práticas de leitura contextualizadas (DUBOC; FERRAZ, 2011).

Em uma apostila publicada em 2005, Kleiman discorre sobre o letramento afirmando que não se trata de método, alfabetização ou habilidade, mas que contempla todos esses aspectos. De fato, o letramento envolve capacidades de uso da língua em diferentes esferas linguísticas e sociais, segundo as diversas necessidades comunicativas.

A respeito disso, Monte Mór (2015) explana que muitas são as habilidades necessárias para a vivência em uma sociedade globalizada e que a postura crítica representa uma dessas habilidades. De acordo com estudos acerca dos letramentos, é natural a associação entre língua e práxis social. À vista disso, Monte Mór (2015) ainda corrobora que é inerente ao letramento crítico o entendimento de que a língua possui caráter político e, consequentemente, relações de poder envolvidas. Em outras palavras, a língua não é neutra, portanto, as práti- cas de leitura também não são. Assim, é importante que o ensino dessa habilidade oriente o aluno a construir um posicionamento crítico reflexivo acerca da sociedade em que está inserido.

\section{Procedimentos metodológicos}

Para o desenvolvimento do presente trabalho, realizamos um recorte da pesquisa vinculada ao Programa Institucional de Bolsas de Iniciação Científica (PIBIC/CNPq 2019/2020). Sob o título $O$ livro didático de Língua Inglesa e o Exame Nacional do Ensino Médio (ENEM): investigação sobre práticas de compreensão leitora da Educação Básica, propusemo-nos a analisar como são orientadas as atividades de leitura nos livros didáticos de Língua Inglesa do Ensino Médio com vistas ao letramento crítico.

Diante disso e a partir de um direcionamento metodológico descritivo-interpretativo, de ordem quali-quantitativa, analisamos as atividades de leitura presentes na coleção Way to Go (2016) segundo as teorias dos gêneros. Com intuito de alcançar os objetivos traçados, norteamo-nos pelas questões a seguir elencadas: (1) Quais gêneros são trabalhados nas atividades de leitura? (2) O autor do livro didático aborda as características dos gêneros utilizados nas atividades de leitura? (3) As atividades de compreensão de texto orientam 
os estudantes a desenvolverem o senso crítico? Se afirmativo, como?

Para responder a primeira questão de pesquisa, fizemos um levantamento das atividades de leitura existentes nos livros e observamos a presença dos gêneros textuais, nomeando-os. Como critérios de análise, além da indicação do gênero, delimitamos: propósito comunicativo, forma composicional e suporte/meio de divulgação. Com a finalidade de atender a segunda questão, procuramos identificar esses aspectos nas atividades propostas. Além disso, buscamos, também, averiguar se as atividades de leitura promovem o desenvolvimento do senso crítico e, para tanto, observamos no material a presença de marcas linguísticas que instiguem o posicionamento do aluno, atendendo a terceira questão de pesquisa.

Por fim, realizamos uma análise interpretativa de três atividades, uma proveniente de cada livro, com o intuito de apontar uma amostra qualitativa do material analisado. $\mathrm{Na}$ seção a seguir, apresentamos e discutimos os resultados obtidos neste estudo.

\section{Resultados e discussão dos dados}

A partir das informações coletadas na $12^{\mathrm{a}}$ Diretoria Regional de Educação e Cultura (DIREC) da cidade de Mossoró $\mathrm{RN}$, tomamos conhecimento que a coleção Way to Go (2016) é utilizada em uma das maiores escolas da cidade. Abaixo, destacamos o material didático investigado.

Figura 1 - Coleção Way to Go
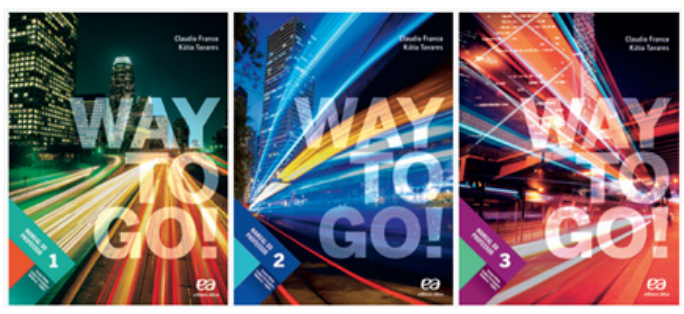

Fonte: https://colecaoway.com.br/pubs/pnld2018/

Essa coleção apresenta uma disposição que favorece um contato com a leitura de forma processual. Cada livro possui um total de oito unidades, instigando o engajamento dos alunos com a temática a ser trabalhada a partir da seção de Warming up. A segunda seção é voltada para o estudo da compreensão leitora, foco de nossas investigações, apresentando atividades de pré e pós-leitura. Para Solé (1998), essas atividades são necessárias devido aos sentidos de um texto serem construídos em conformidade com o leitor, com seus conhecimentos prévios, com o texto em si e com o objetivo de leitura.

Destacamos que, embora a seção seja direcionada à leitura, as atividades também envolvem o uso de outras habilidades. A esse respeito, Oliveira (2015) ressalta a importância de as quatro habilidades linguísticas serem tratadas de forma integrada, já que nos eventos comunicativos reais, elas se apresentam em conjunto. 
$\mathrm{O}$ autor afirma que "os usos reais da língua envolvem, pelo menos, duas habilidades" (OLIVEIRA, 2015, p. 71). Nesse sentido, é importante que o professor faça uso de pré e pós-atividades que abranjam habilidades diferentes daquelas que foram focadas inicialmente em sala. Ao entendermos que o livro didático é um guia para o ensino da língua, percebemos que o objeto de análise deste trabalho se adequa por possibilitar essa interação entre as habilidades.

Tendo em vista que são muitas as discussões teóricas atreladas aos gêneros textuais e ao ensino de leitura, elencamos alguns critérios para realização da análise dos dados. Primeiramente, detivemo-nos na seção voltada à leitura, que na coleção estudada é identificada como Reading, e verificamos, então, se há a presença de gêneros de textos e, consequentemente, quais desses são abordados.

Depois disso, debruçamo-nos a verificar se as atividades promovem o estudo das características dos gêneros. À vista disso, observamos as informações acerca do propósito comunicativo, forma composicional e suporte/meio de divulgação do texto. Por fim, averiguamos se os exercícios promovem meios de os alunos se posicionarem criticamente. A seguir, apresentamos uma tabela demonstrativa dos resultados obtidos em nossa pesquisa. Nela, indicamos por percentual os gêneros textuais, assim como apontamos os demais critérios.

Tabela 1 - Coleção Way to Go

\begin{tabular}{|c|c|c|c|c|c|c|}
\hline \multicolumn{7}{|c|}{ COLEÇÃO WAY TO GO } \\
\hline \multirow[b]{2}{*}{ Livro } & \multirow{2}{*}{$\begin{array}{l}\text { Indicação } \\
\text { do gênero } \\
\text { textual }\end{array}$} & \multirow{2}{*}{$\begin{array}{l}\text { Gênero } \\
\text { Textual }\end{array}$} & \multicolumn{3}{|c|}{ Característica do gênero } & \multirow[b]{2}{*}{$\begin{array}{l}\text { Posicionamento } \\
\text { crítico }\end{array}$} \\
\hline & & & $\begin{array}{c}\text { Propósito } \\
\text { comunicativo }\end{array}$ & $\begin{array}{c}\text { Forma } \\
\text { composicional }\end{array}$ & Suporte & \\
\hline $\begin{array}{l}\text { Way to } \\
\text { Go } 01\end{array}$ & $100 \%$ & $\begin{array}{l}\text { Infográfico, Mapa mental, } \\
\text { Artigo, Biografia e Poema }\end{array}$ & $12,5 \%$ & $100 \%$ & $100 \%$ & $100 \%$ \\
\hline $\begin{array}{l}\text { Way to } \\
\text { Go } 02\end{array}$ & $75 \%$ & $\begin{array}{l}\text { Artigo, Carta de aconselha- } \\
\text { mento, Infográfico, Carta, } \\
\text { entrevista }\end{array}$ & $25 \%$ & $62,5 \%$ & $100 \%$ & $100 \%$ \\
\hline $\begin{array}{l}\text { Way to } \\
\text { Go } 03\end{array}$ & $75 \%$ & Artigo e Resumo & $50 \%$ & $75 \%$ & $100 \%$ & $100 \%$ \\
\hline
\end{tabular}

Fonte: Dados levantados pelas autoras

Diante dos dados explícitos na tabela, podemos observar que o livro Way to Go ( $1^{\text {a }}$ série) indica gênero textual em todas as atividades de leitura da obra. Nelas, são trabalhados os gêneros infográfico, mapa mental, artigo, biografia e poema. Com relação ao nosso segundo critério de análise, que diz respeito às características do gênero, os resultados obtidos são de $12,5 \%$ de indicação do propósito comunicativo, $100 \%$ de orientação quanto à forma composicional $\mathrm{e}$ $100 \%$ de apresentação do suporte/meio 
de divulgação. Quanto a esse critério, é importante ressaltar que "o suporte não é neutro e o gênero não fica indiferente a ele" (MARCUSCHI, 2008, p. 174). Por fim, a instrução para o despertar do senso crítico do aluno foi realizada em todas as atividades de pós-leitura com um resultado de $100 \%$ de indicação.

No segundo livro da coleção, Way to Go ( $2^{\mathrm{a}}$ série), averiguamos que a indicação de gênero textual caiu para $75 \%$, ou seja, das oito seções de leitura, somente seis trabalham com gêneros textuais. Nas demais unidades, são encontrados trechos de livros e, acerca disso, entendemos que excertos não são gêneros textuais, posto que anulam algumas características que a estes são necessárias, como o propósito comunicativo, por exemplo. Diante disso, compreendemos que a falta de um gênero autêntico atrapalha o desenvolvimento concreto da habilidade de compreensão leitora, dado que "o reconhecimento do gênero tipifica as possíveis ações e intenções sociais” (BAZERMAN, 2006, p. 28).

Nesse mesmo livro da coleção, os gêneros abordados são artigo, carta de aconselhamento, infográfico, carta e entrevista. Segundo Solé (1998), o leque de gêneros também afeta a compreensão que se tem deles, uma vez que quanto mais familiarizado com o gênero, melhor será a compreensão por parte do leitor. Dentre as características do gênero, a indicação do propósito comunicativo apresentou uma taxa de indicação de apenas
$25 \%$ no resultado. A forma composicional, por sua vez, sofreu alteração para 62,5\%, ou seja, cinco unidades trazem essa informação. Por último, percebemos que o suporte é mostrado em todas as lições, como também as orientações para o desenvolvimento do senso crítico.

Assim como no livro anterior, o Way to Go ( $3^{\text {a }}$ série) exibe $75 \%$ de indicação de gênero textual, no entanto trabalha somente os gêneros artigo e resumo, o que a nosso ver é preocupante pelo fato de o livro abordar somente dois exemplares de gênero. $\mathrm{O}$ gênero de texto é negligenciado nas lições 1 e 8, contemplando excertos de livros, descartados em nosso estudo. Dessa forma, tendo em conta que a leitura é um importante meio de aprendizado, acreditamos que o ideal é um estudo baseado em gêneros variados (ANTUNES, 2003), que possibilite um contato maior com diferentes práticas comunicativas.

No tocante à indicação do propósito comunicativo, essa é feita em $50 \%$ da obra, isto é, em 4 unidades. Já a orientação para a forma composicional apresenta um pequeno aumento para $75 \%$. Da mesma maneira que os livros anteriores, o suporte/meio de divulgação é mostrado em 100\% das lições. Em concordância a isso, estão as atividades de pós-leitura, que orientam que o discente se posicione.

Marcuschi esclarece que "compreender um texto envolve mais do que o simples conhecimento da língua e a reprodução de informações" (2005, p. 58). 
Nesse sentido, é relevante frisar que a coleção apresenta ao final da seção de leitura de cada unidade uma atividade chamada de "ler para pensar criticamente", na qual os alunos são levados a discutir sobre as questões abordadas no texto. Desta forma, a maneira pelo qual o texto é trabalhado pode contribuir para a formação social e crítica dos alunos.

Abordamos, a partir deste momento, a análise de três atividades, uma de cada livro. No livro da primeira série do
Ensino Médio, Way to Go 1 (2016), encontramos na unidade I o gênero infográfico (figura 2). A seção de leitura é dividida do seguinte modo: antes da leitura (Before reading), leitura (Reading), leitura para compreensão geral (Reading for general comprehension), leitura para compreensão detalhada (Reading for detailed comprehension) e ler para pensar criticamente (Reading for critical thinking). Essa estruturação da seção de leitura é a mesma para toda a coleção.

Figura 2 - Infográfico (unidade 1, p. $23-24)^{2}$

\section{BEFORE READING}

1. Answer the questions below.

a. Are you a high-tech person? If so, do you use technology to study?

b. Do your teachers use technology in the classroom? If so. what for?

2. Turn over the page and, before reading the text. look at the pictures, the title and the layout Then choose the correct item that completes each sentence below ( $\mathbf{A}$ or $\mathbf{m})$. Write the answers in your notebook.

a. The text contains

a a main topic only.

ma main topic and four subtopics.

IIP Observe o ticula os yiblitulen.

as imagens e o leimute do texta

isso sjudari vocl a compreundo-ia.

b. The title and subheadings suggest that technology in the classroom is viowed as something

A positive.

a negative.

\section{READING}

Now road the tent quichy le check your predictions

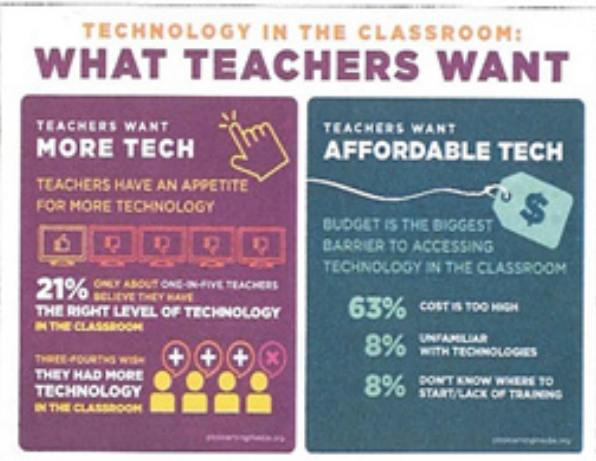

田

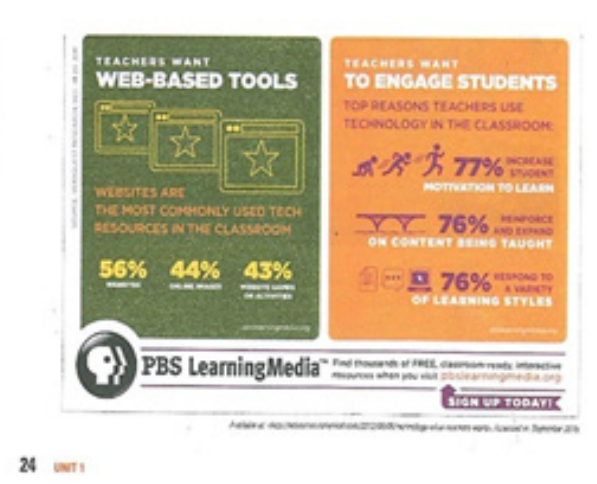

Fonte: Way to Go 1, 2016 (imagem adaptada) 
A disposição da seção indica que seus idealizadores entendem a importância de um estudo processual da habilidade de leitura, iniciando com atividade de ativação do conhecimento prévio dos alunos e avançando até alcançar um posicionamento crítico social deles (OLIVEIRA, 2015). A atividade em questão se encontra na primeira unidade do livro e contempla todos os critérios de análise considerados neste estudo, são estes: indicação do gênero, propósito comunicativo, forma composicional e suporte/ meio de divulgação.

Nesta primeira unidade, os autores apresentam um infográfico sobre a necessidade que os professores sentem acerca do uso da tecnologia em sala de aula. Logo, nas atividades de mobilização dos conhecimentos prévios dos alunos, na subseção antes da leitura, há uma atividade que expõe o gênero textual trabalhado, indica o propósito comunicativo de apresentar uma informação de forma rápida e apresenta características da forma composicional do gênero, que são confirmadas ao visualizar o texto na seção seguinte, leitura. A atividade pede que o aluno observe a estrutura do gênero, título, leiaute, imagens e outros aspectos. Fazendo isso, o aluno, por meio do exemplo, é exposto à forma prototípica de manifestação do infográfico.

$\mathrm{Na}$ imagem abaixo de cada quadro informativo e do infográfico por inteiro, há uma informação do website o qual o infográfico discutido e outros podem ser encontrados, indicando, assim, o meio de divulgação, um dos critérios avaliados neste estudo. Além disso, há uma fonte abaixo do texto, indicando o website que os autores utilizaram para obtê-lo. Ao final da seção de leitura, há uma atividade chamada ler para pensar criticamente, na qual os alunos são levados a discutir sobre as questões abordadas pelo texto, suscitando um posicionamento reflexivo dos estudantes (figura 3).

Figura 3 - Ler para pensar criticamente ${ }^{3}$ READING FOR CRITICAL THINKING

Discuss the following questions with your classmates.

a. According to the text, teachers use technology in the classroom to engage students. Do you

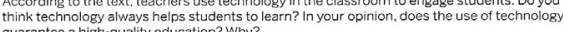
guarantee a high-quality education? Why?

b. Do you think high cost is one of the barriers to accessing technology in Brazilian schools?

In your opinion, what are other possible barriers?

Studying with Technology 25

Fonte: Livro Way to Go 1 (2016).

Nessa atividade, é sugerido ao aluno discutir com os colegas as duas perguntas que seguem. À vista disso, entendemos que o estudante tanto tem a oportunidade de expor o que pensa como pode tomar conhecimento do posicionamento do colega. Observamos nessa proposta pistas textuais que indicam a participação do aluno de forma ativa e crítica a partir do material o qual foi exposto. O estudante é levado a dizer o que pensa, dar sua opinião acerca do assunto e interagir em sala com o professor e com os outros alunos. Para chegar a esse resultado, consideramos as marcas linguísticas presentes em: você acha...? 
(do you think...?), por quê? (why?), na sua opinião...? (in your opinion...?).

No livro da segunda série do Ensino Médio, Way to Go 2 (2016), observamos na quarta unidade que não há indicação de gênero no texto apresentado na seção de leitura (Reading), visto que se trata de um excerto de livro (figura 4). Em nosso estudo, não compreendemos ex- certo de livro como exemplar de gênero textual, posto que não contempla os "padrões sociocomunicativos característicos definidos por composições funcionais, objetivos enunciativos e estilos concretamente realizados na interação de forças históricas, sociais, institucionais e técnicas" (MARCUSCHI, 2008, p. 155) que pertencem aos gêneros.

Figura 4 - Excerto de livro (unidade 4, p. 72) ${ }^{4}$

\section{READING}

Now read the text to check your predictions.

Anorexia nervosa is a very serious disease that can be fatal. It is characterized by excess weight loss and emaciation even though the patient may perceive herself to be "fat". This disease is more common in females than males. These patients may starve to death.

Orthorexia is similar to anorexia, but the reason for the abnormal food-related behavior is not a wish to be thin or a perception of being fat. Rather, these people want to eat only healthy and pure foods to the point of malnutrition and even starvation. They may avoid the "wrong" or "unhealthy" foods such as those made from animals or fats, or those that have preservatives.

Butimia nervosa is a disease of binge eating followed by self-induced purges (vomiting. laxative use, enemas) to get rid of the food just eaten. This can lead to serious heart, kidney. and other diseases as well as depression.

Fatal cases have been reported.

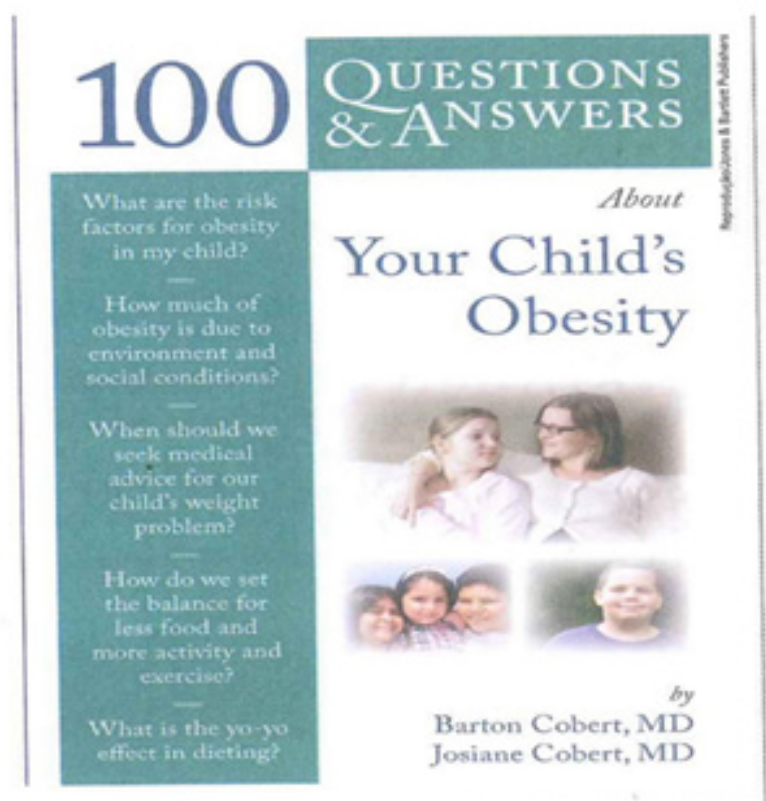

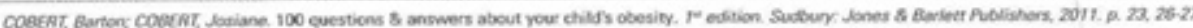

Fonte: Livro Way to Go 2, 2016 (imagem adaptada).

Nessa unidade, os autores da coleção apresentam um trecho do livro 100 questions and answers about your child's obesity, que diz respeito a hábitos ali- mentares e obesidade infantil. Por não se tratar de um gênero textual, não tivemos como analisá-lo em termos de propósito comunicativo e forma composicional. Os 
autores indicam o suporte desse texto, referenciando o livro utilizado. É importante frisar, ainda, que na subseção antes da leitura, é proposto ao aluno que responda uma questão acerca da estrutura do texto (figura 5). Contudo, não consideramos como uma atividade que trabalha a forma composicional do gênero, uma vez que o texto utilizado não é um gênero textual.

Figura 5 - Antes da leitura ${ }^{5}$

\section{BEFORE READING}

1. Turn over the page and, before reading the text, look at the structure and the source of the text. Then choose the correct item that completes each sentence below ( $\Delta$, a or 0 ). Write the answers in your notebook.

a. The text is in the form of

$\Delta$ an article. $\quad \square$ a questionnaire. o questions and answers.

Fonte: Livro Way to Go 2 (2016).

Continuando a atividade, na subseção leitura para compreensão geral, verificamos a presença de uma questão acerca do propósito do texto. Contudo, assim como na questão mostrada anteriormente, não foi contemplada como uma indicação de propósito comunicativo do gênero. Ao final da unidade, na subseção ler para pensar criticamente, os autores propõem questões que incentivam o desenvolvimento do posicionamento crítico do aluno (figura 6). Assim, a atividade contempla nossa última questão de pesquisa.

Com intuito de verificar se esse último critério é atendido, observamos as pistas textuais presentes. Nessa unidade, percebemos o uso de frases como: em sua opinião...? (in your opinion...?), você acha que...? (do you think...?), se sim, como? (if so, how?). Todas orientam para a participação dos alunos, por meio do compartilhamento de ideias.

Figura 6 - Ler para pensar criticamente ${ }^{6}$

\section{READING FOR CRITICAL THINKING}

Discuss the following questions with your classmates.

a. In your opinion, do people usually see eating disorders as a health problem or as a matter of personal choice? What are the consequences of such a view?

b. Do you think family members can play an important role in the prevention and in the overcoming of eating disorders? If so, how?

Fonte: Livro Way to Go 2 (2016).

No livro da terceira série do Ensino Médio (Way to Go 3), identificamos na unidade sete $o$ gênero textual resumo (figura 7) e o apresentamos a seguir. 
Figura 7 - Resumo (unidade 7, p. 125-126) ${ }^{7}$

3. Turn over the fage and, before reading the text, look at the picture on the book cover, the source and the structure of the text. Then choose what you expect to be correct about it ( $\mathbf{a}$ or a). Write the answers in your notebook. = a, b. A

a. The text is ashort

4 review of Jane Eyre.

- summary of Jane Eyre.

\section{READING}

Now read the text to check your predictions.

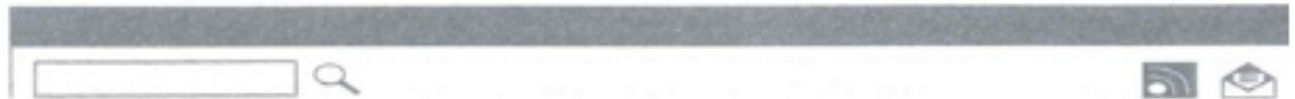

\section{Jane Eyre}

(Charlotte Brente)

Jane Eyre is a young orphan being raised by Mrs. Reed. her cruel, wealthy aunt. One day, as punishment tor fighting with her bullying cousin John Reed. Jane's aunt imprisons Jane in the red-room, the room in which Jane's Uncle Reed died. While locked in, lane, believing that she sees her uncle's ghost, screams and faints. She wakes to find herselr in the care of the cordial servant Bessie and the kindly pharmacist Mr. Lloyd. who sugcests to Mrs. Reed that lane be sent away to school.

Once at the Lowood School, Jane finds that her He is far from ideal. The school's headmaster is Mr. Brocklehurst. a cruel, hypocritical, and abusive man. At Lowood. Jane befriends a young girl named Helen Burns, whose attitude toward the sehool's miseries is both helpful and displeasing to Jane. A massive typhus epidemic sweeps Lowood, and Helen dies. After a group of more sympathetic gentlemen takes Brocklehurst's place, Jane's life improves dramatically. She spends eight more years at Lowood, six as a student and two as a teacher.

After teaching for two years. Lane accepts a governess position. Jane's employer is a man named Rochester. with whom fane finds herself falling secretly in love. She saves Rochester from a fire one night, which he claims was started by a drunken servant. Rochester proposes to Jane, who accepts.

The wedding day arrives, and as Jane and Mr. Rochester prepare to exchange their vows, the volce of Mr. Mason cries out that Rochester already has a wife. Bertha. Mason introduces himself as her brother. Mr. Mason testifies that Bertha. whom Rochester married when he was a young man in Jamaica. is still alive. Rochester does not deny Mason's claims. but he explains that Bertha has gone mad and he keeps her hidden. Bertha was the real cause of the mysterious fire earlier in the story. Knowing that it is impossible for her to be with Rochester. Jane runs away.

Poor and hungry. Jane is forced to sleep outdoors and beg for food. At last. three siblings - Mary. Diana. and St. John Fivers - take her in. St. John surprises her one day by declaring that her uncle, John Eyre, has died and left her a large fortune. When Jane asks how he received this news, he reveals that lane and the Riverses are cousins.

St. John decides to travel to India as a missionary. and he urges Jane to accompany him - as his wife. Jane refuses to marry heir cousin because she does not love him. Jane realizes that she cannot abandon forever the man she truly lowes. She hurries back to Rochester's house and finds that it has been burned by Bertha Mason, who lost her life in the fire. Rochester saved the servants but lost his eyesight and one of his hands. Jane travels on to Rechester's new resajdence.

Rochester and Jane rebuild their relationship and soon marry. At the end of her story. lane writes that she has been married for ten happy years and that she and Rochester enioy perfect equality in their life together. She says that after two years of blindness. Rochester regained sight in one eye and was able to behold their first son at his birth.

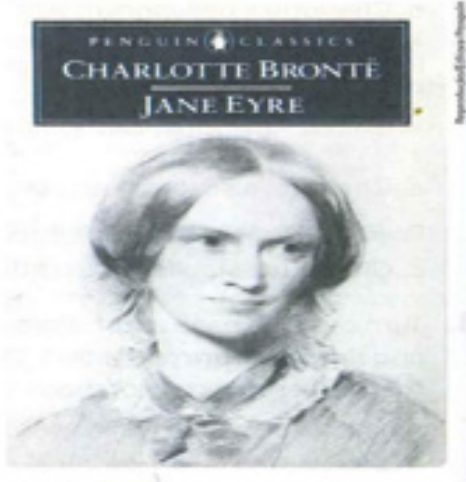

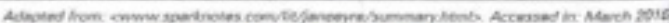

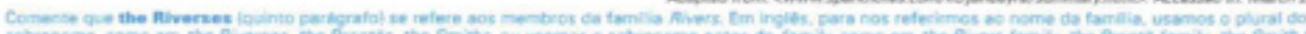

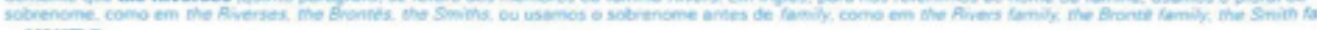
UNIT ?

Fonte: Livro Way to Go 3, 2016 (imagem adaptada). 
Nessa unidade, percebemos que a atividade é contextualizada. No tópico de pré-leitura, é apontado o gênero textual resumo, assim como algumas informações pertinentes ao conteúdo a ser lido. Trata-se do resumo de um livro da escritora inglesa Charlotte Brontë, o romance Jane Eyre. Logo após a contextualização da leitura que se aproxima, é pedido que os alunos se atenham às características composicionais do texto, indicando a forma composicional e nome do gênero a ser trabalhado, critérios importantes ao nosso estudo. Logo após a leitura do resumo, é apresentado em forma de pergunta o objetivo do texto, ou seja, seu propósito comunicativo. É importante destacar que abaixo do gênero, temos a fonte apontada. As informações apresentadas são trabalhadas para que os alunos formem a compreensão do texto e, por fim, tem-se o momento de discussão da temática, suscitando a opinião crítica dos alunos a respeito do tema abordado, na subseção ler para pensar criticamente (figura 8).

Figura 8 - Ler para pensar criticamente ${ }^{8}$ READING FOR CRITICAL THINKING

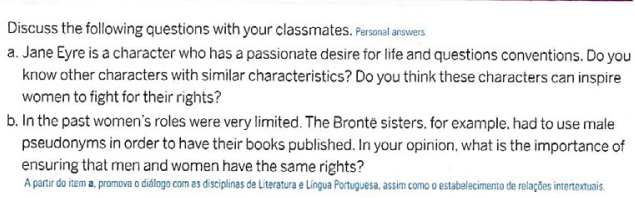

Fonte: Livro Way to Go 3, 2016.
Nessa subseção, podemos notar duas perguntas direcionadas aos alunos que instigam seu posicionamento. Percebemos isso a partir das pistas textuais: você sabe...? (do you know...?), você acha...? (do you think...?), em sua opinião...? (in your opinion...?), qual a importância...? (what is the importance...?). Desta forma, compreendemos que, nessa unidade, a seção de leitura se adequa a todos os critérios de análise contemplados em nosso estudo.

\section{Considerações finais}

O presente trabalho teve por objetivo analisar como são orientadas as atividades de leitura nos livros didáticos de Língua Inglesa do Ensino Médio com vistas ao letramento crítico e, para tanto, investigamos os livros didáticos da coleção Way to Go (2016). Com o intuito de responder às nossas questões de pesquisa, estabelecemos os seguintes critérios de análise: indicação de gênero, propósito comunicativo, forma composicional, suporte e presença de atividades que orientem para o posicionamento crítico dos alunos.

Para Bakhtin, gêneros são "tipos relativamente estáveis de enunciados" (2003, p. 261) presentes em toda e qualquer atividade humana. Levando isso em consideração, entendemos a importância de a língua ser ensinada a partir do emprego de gêneros textuais. Diante de 
nossos resultados, podemos inferir que a coleção pesquisada trabalha a leitura a partir de uma vasta variedade de gêneros, deixando de atender ao nosso primeiro critério em poucas unidades.

No tocante ao propósito comunicativo, percebemos que são grandes as lacunas nos três livros da coleção. Os livros Way to Go da primeira e segunda série atendem a esse critério somente em duas unidades cada, já o livro destinado aos alunos da terceira série atende apenas em quatro unidades. À vista disso, Marcuschi afirma que "quando dominamos um gênero textual, não dominamos uma forma linguística e sim uma forma de realizar linguisticamente objetivos específicos em situações sociais particulares" (2008, p. 154). Esses objetivos são o que podemos chamar de propósito comunicativo. Se esses se ausentam nas propostas dos livros, uma parte essencial deixa de ser trabalhada.

Com relação à forma composicional dos textos, vimos que a coleção cumpre o critério na maioria das atividades. É a partir da forma composicional que o aluno pode entender melhor sobre a constituição do gênero, ou, como nas palavras de Jales, "como o gênero deve ser textualmente organizado" (2007, p. 50).

A penúltima categoria de análise recai sobre o suporte. Verificamos que todas as unidades dos três livros pesquisados apresentam essa indicação. Sabemos que o suporte é o meio pelo qual o gênero é concretizado e muitas vezes pode interferir em sua denominação, como já discutido por Marcuschi (2008).

Por fim, averiguamos que a coleção trabalha a leitura em uma perspectiva interacional de língua, já que oferece meios de os alunos desenvolverem $o$ senso crítico. Todas as atividades dos livros possuem uma seção destinada à discussão das temáticas estudadas. Nessa seção, os alunos têm a oportunidade de pensar mais sobre aquilo que foi lido, de discutir suas ideias entre si e de formular uma compreensão própria do texto.

Desta forma, é importante pensar em um ensino de língua a partir de textos concretos, ou seja, de gêneros textuais. $\mathrm{O}$ ensino da leitura somente traz resultados satisfatórios quando oferece meios de os alunos construírem sua compreensão acerca daquilo que leem (SOLÉ, 1998). No tocante ao livro didático, entendemos que este constitui uma importante ferramenta para um ensino que favoreça um estudo comunicativo de língua. Nesse sentido, a leitura é, portanto, um processo interativo entre o leitor e o texto, devendo ser ensinada a partir da observância desse aspecto. 


\section{Textual genres and the teaching of reading comprehension: an analysis of high school textbooks}

\section{Abstract}

Regarding the relevance of textual genres to language teaching, this paper aims to analyse how reading activities are oriented in English language textbooks of high school in order to critical literacy. This research results from studies linked to the Programa Institucional de Bolsas de Iniciação Científica (PIBIC/ CNPq 2019/2020). In this sense, we analysed the Way to Go collection and as parameters of analysis, we have taken into account the indication of textual genre, communicative purpose, compositional textual form, support and guidance to students' critical thinking. Through the results, we noticed that most activities are based on textual genres, indicating compositional form, support and with attention to the development of students' critical thinking. In relation to communicative purpose, we realized that many activities do not reach this criterion. Therefore, the collection presents a partial adequacy to the theories related to this study.

Keywords: Textual genres; Reading; Textbook; English

\section{Notas}

1 Autores: Claudio Franco e Kátia Tavares.

2 1. Responda as questões abaixo. 2. Vire a página e, antes de ler o texto, olhe as imagens, o título e o leiaute. Leitura: Agora leia o texto rapidamente e cheque suas predições.

3 Discuta as seguintes questões com seus colegas.
4 Leitura: Agora leia o texto e cheque suas predições.

5 1. Vire a página e, antes de ler o texto, olhe a estrutura e a fonte. Depois escolha o item correto que completa cada sentença abaixo. Escreva as respostas em seu caderno.

6 Discuta as seguintes questões com seus colegas. 3. Vire a página e, antes de ler o texto, olhe a imagem na capa do livro, a fonte e a estrutura. Leitura: agora leia o texto e cheque suas predições.

8 Discuta as seguintes questões com seus colegas.

\section{Referências}

ANTUNES, Maria Irandé Costa Morais. Língua, gêneros textuais e ensino: considerações teóricas e implicações pedagógicas. Perspectiva: Revista do Centro de Ciências da Educação. Universidade Federal de Santa Catarina. Centro de Ciências da Educação, Florianópolis, v. 20, n. 1, p. 65-75, 2002.

ANTUNES, Maria Irandé Costa Morais. Aula de português: encontro e interação. São Paulo: Parábola Editorial, 2003.

ANTUNES, Maria Irandé Costa Morais. Língua, texto e ensino: outra escola possível. São Paulo: Parábola Editorial, 2009.

BAKHTIN, Mikhail. Os gêneros do discurso. In:__. Estética da criação verbal. 4. ed. São Paulo: Martins Fontes, 2003. p. 261-306.

BAZERMAN, Charles. A vida do gênero, a vida em sala de aula. In: HOFFNAGEL, Judith Chambliss; DIONÍSIO, Ângela Paiva (org.). Gênero, agência e escrita. São Paulo: Cortez, 2006. p. 23-43.

BRASIL, Secretaria de Educação Fundamental. Parâmetros Curriculares Nacionais: terceiro e quarto ciclos do ensino fundamental: língua estrangeira. Brasília, MEC/SEF, 1998.

BRASIL. Ministério da Educação. Secretaria da Educação Fundamental. Parâmetros Curriculares Nacionais: língua portuguesa. 3. ed. Brasília, 2001. 
BRASIL, Ministério da Educação. Secretaria de Educação Básica. Orientações Educacionais Complementares aos Parâmetros Curriculares Nacionais (PCN+). Linguagens e códigos e suas tecnologias, língua estrangeira. Brasília: MEC, 2006.

BRASIL, Ministério da Educação. Secretaria de Educação Básica. Orientações curriculares para o ensino médio (OCEM). Linguagens e códigos e suas tecnologias, conhecimentos de língua estrangeira. Brasília: MEC, 2006.

BRASIL. Ministério da Educação. Secretaria da Educação Básica. Base nacional comum curricular. Brasília: MEC, 2018.

DUBOC, Ana Paula; FERRAZ, Daniel Mello. Letramentos críticos e formação de professores de inglês: currículos e perspectivas em expansão. Revista X, Paraná, v. 1, p. 19-32, 2011.

FRANCO, Cláudio de Paiva; TAVARES, Kátia. Way to Go: língua estrangeira moderna. 2. ed. São Paulo: Ática, 2016.

JALES, Adriana Morais. Os gêneros textuais e o ensino da produção de texto: análise de propostas em livros didáticos de Língua Inglesa. 2007. Dissertação (Mestrado em Linguística Aplicada) - Universidade Estadual do Ceará - UECE, Fortaleza, 2007.

KLEIMAN, Angela. Preciso "ensinar" o letramento? Não basta ensinar a ler e escrever?. Campinas: UNICAMP: Cefiel \& MEC: Secretaria de Ensino Fundamental, 2005.

KOCH, Ingedore Villaça; ELIAS, Vanda Maria. Gêneros textuais. Ler e compreender: os sentidos do texto. 3. ed. São Paulo: Contexto, 2012.

MARCUSCHI, Luiz Antônio. Gêneros textuais: definição e funcionalidade. In: DIONÍSIO, Ângela Paiva; MACHADO, Anna Rachel; BEZERRA, Maria Auxiliadora (org.). Gêneros textuais \& ensino. 2. ed. Rio de Janeiro: Lucerna, 2003. p. 19-36.
MARCUSCHI, Luiz Antônio. Compreensão de texto: algumas reflexões. In: DIONÍSIO, Ângela Paiva; BEZERRA, Maria Auxiliadora (org.). $O$ livro didático de português: múltiplos olhares. 3. ed. Rio de Janeiro: Lucerna, 2005. p. 48-61.

MARCUSCHI, Luiz Antônio. Gêneros textuais no ensino de língua. In: Produção textual, análise de gêneros e compreensão. São Paulo: Parábola Editorial, 2008.

MONTE MÓR, Walkyria. Crítica e letramentos críticos: reflexões preliminares. In: ROCHA, Cláudia Hilsdorf; MACIEL, Ruberval Franco (org.). Língua estrangeira e formação cidadã: por entre discursos e práticas. 2. ed. Campinas: Pontes editores, 2015. p. 31-50.

OLIVEIRA, Luciano Amaral. Aula de inglês: do planejamento à avaliação. 1. ed. São Paulo: Parábola Editorial, 2015.

SOLÉ, Isabel. Estratégias de Leitura. Tradução de: Cláudia Schilling. 6. ed. Porto Alegre: Penso, 1998. 